Ferrata Storti Foundation

\title{
Immune marker changes and risk of multiple myeloma: a nested case-control study using repeated pre-diagnostic blood samples
}

Haematologica 2019

Volume 104(12):2456-2464

\section{Correspondence: \\ FLORENTIN SPÄTH \\ florentin.spaeth@umu.se \\ Received: January 20, 2019. \\ Accepted: April 3, 2019. \\ Pre-published: April 4, 2019.}

doi:10.3324/haematol.2019.216895

Check the online version for the most updated information on this article, online supplements, and information on authorship \& disclosures: www.haematologica.org/content/104/12/2456

(C)2019 Ferrata Storti Foundation

Material published in Haematologica is covered by copyright. All rights are reserved to the Ferrata Storti Foundation. Use of published material is allowed under the following terms and conditions:

https://creativecommons.org/licenses/by-nc/4.0/legalcode. Copies of published material are allowed for personal or internal use. Sharing published material for non-commercial purposes is subject to the following conditions:

https://creativecommons.org/licenses/by-nc/4.0/leǵalcode, sect. 3. Reproducing and sharing published material for commercial purposes is not allowed without permission in writing from the publisher.

\author{
Florentin Späth, ${ }^{1}$ Carl Wibom, ${ }^{1}$ Esmeralda J. M. Krop, ${ }^{2}$ Antonio Izarra \\ Santamaria, ${ }^{1}$ Ann-Sofie Johansson, ${ }^{1}$ Ingvar A. Bergdahl, ${ }^{3}$ Johan Hultdin, ${ }^{4}$ \\ Roel Vermeulen ${ }^{2 \star}$ and Beatrice Melin ${ }^{1 *}$ \\ ${ }^{1}$ Department of Radiation Sciences, Oncology, Umeå University, Sweden; 'Division of \\ Environmental Epidemiology, Institute for Risk Assessment Sciences, Utrecht University, \\ the Netherlands; ${ }^{3}$ Department of Biobank Research, Umeå University, Sweden and \\ ${ }^{4}$ Department of Medical Biosciences, Clinical Chemistry, Umeå University, Sweden
}

${ }^{*} R V$ and $B M$ contributed equally to this work.

\section{ABSTRACT}

$\mathrm{B}$ iomarkers reliably predicting progression to multiple myeloma (MM) are lacking. Myeloma risk has been associated with low blood levels of monocyte chemotactic protein-3 (MCP-3), macrophage inflammatory protein-1 alpha (MIP-1 $\alpha$ ), vascular endothelial growth factor (VEGF), fibroblast growth factor-2 (FGF-2), fractalkine, and transforming growth factor-alpha (TGF- $\alpha$ ). In this study, we aimed to replicate these findings and study the individual dynamics of each marker in a prospective longitudinal cohort, thereby examining their potential as markers of myeloma progression. For this purpose, we identified 65 myeloma cases and 65 matched cancer-free controls each with two donated blood samples within the Northern Sweden Health and Disease Study. The first and repeated samples from myeloma cases were donated at a median 13 and 4 years, respectively, before the myeloma was diagnosed. Known risk factors for progression were determined by protein-, and immunofixation electrophoresis, and free light chain assays. We observed lower levels of MCP-3, VEGF, FGF-2, and TGF- $\alpha$ in myeloma patients than in controls, consistent with previous data. We also observed that these markers decreased among future myeloma patients while remaining stable in controls. Decreasing trajectories were noted for TGF- $\alpha\left(P=2.5 \times 10^{-4}\right)$ indicating progression to MM. Investigating this, we found that low levels of TGF- $\alpha$ assessed at the time of the repeated sample were independently associated with risk of progression in a multivariable model (hazard ratio $=3.5 ; P=0.003$ ). TGF- $\alpha$ can potentially improve early detection of MM.

\section{Introduction}

Multiple myeloma (MM) is one of the most common but still incurable hematologic malignancies. ${ }^{1} \mathrm{MM}$ is preceded by monoclonal gammopathy of undetermined significance (MGUS), ${ }^{2}$ a premalignant precursor, and smoldering multiple myeloma (SMM), characterized as an asymptomatic disease stage. ${ }^{3}$ The annual risk of progression to MM is about $1 \%$ for $\mathrm{MGUS}^{4}$ and $10 \%$ for $\mathrm{SMM}^{5}{ }^{5}$ thus patients with either of these conditions require life-long follow-up. ${ }^{6}$ The most well established risk factors for progression to $\mathrm{MM}$ are the type and size of the monoclonal (M)-protein, the free light chain (FLC) ratio, immunoparesis, and the number of plasma cells in the bone marrow. ${ }^{7,8}$ Nevertheless, there is a lack of reliable biomarkers predicting which MGUS and SMM patients will progress to MM and which will not. ${ }^{9,10}$

Plasma proteome profiling has been suggested to be of potential value for risk stratification of MGUS and SMM. ${ }^{11}$ Low blood levels of six cytokines and growth factors have been associated with myeloma risk: monocyte chemotactic protein-3 
(MCP-3), macrophage inflammatory protein-1 alpha (MIP$1 \alpha)$, vascular endothelial growth factor (VEGF), fibroblast growth factor-2 (FGF-2), fractalkine, and transforming growth factor-alpha (TGF- $\alpha){ }^{12}$ However, the study by Vermeulen et al. ${ }^{12}$ that documented these associations did not allow investigation of changes in immune markers in relation to the risk of progression to full-blown disease.

Herein we aimed to replicate the inverse association between myeloma risk and blood levels of MCP-3, MIP$1 \alpha$, VEGF, FGF-2, fractalkine, and TGF- $\alpha$ observed by Vermeulen et al. ${ }^{12}$ We hypothesized that pre-diagnostic marker levels might be useful for predicting progression to MM. To this end, we analyzed MCP-3, MIP-1 $1 \alpha$, VEGF, FGF-2, fractalkine, TGF- $\alpha,{ }^{12}$ and four additional markers that have been related to MM pathobiology - macrophage inflammatory protein-1 beta (MIP-1 $\beta),{ }^{13}$ interleukin (IL)-13, ${ }^{14}$ tumor necrosis factor-alpha (TNF- $\left.\alpha\right),{ }^{15}$ and IL-10 ${ }^{16}$ - in repeated pre-diagnostic plasma samples from 65 myeloma cases and 65 matched cancer-free controls. The utility of the candidate biomarkers in the prediction of the development of MM was evaluated by means of a multivariable model including known risk factors for progression.

Table 1. Characteristics of the study population and the blood samples.

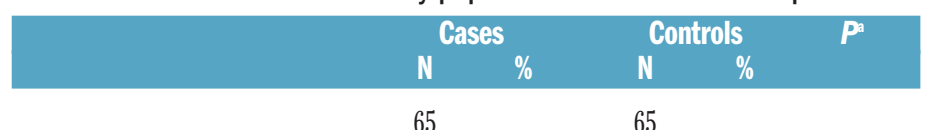

Age at sample collection, years

\begin{tabular}{lccccc} 
Baseline sample, mean (range) & 51 & $(30-69)$ & 51 & $(30-68)$ & \\
Repeated sample, mean (range) & 59 & $(40-74)$ & 59 & $(40-74)$ & \\
$\quad$ Sex & & & & & \\
$\quad$ Female & 48 & 73.8 & 48 & 73.8 & \\
$\quad$ Male & 17 & 26.2 & 17 & 26.2 & \\
$\quad$ Body mass index & & & & & \\
$\quad$ Baseline sample, mean (SD) & 26.1 & $(3.8)$ & 25.4 & $(4.0)$ & 0.32 \\
$\quad$ Repeated sample, mean (SD) & 26.7 & $(3.7)$ & 26.6 & $(4.0)$ & 0.96 \\
$\quad$ Smoking status & & & & & \\
$\quad$ Baseline sample & & & & & 0.94 \\
$\quad$ Non-smoker & 38 & 58.5 & 40 & 61.5 & \\
$\quad$ Current smoker & 15 & 23.1 & 14 & 21.5 & \\
$\quad$ Former smoker & 12 & 18.4 & 11 & 17.0 & \\
$\quad$ Repeated sample & & & & & 0.90 \\
$\quad$ Non-smoker & 41 & 63.1 & 42 & 64.6 & \\
$\quad$ Current smoker & 14 & 21.5 & 12 & 18.5 & \\
$\quad$ Former smoker & 10 & 15.4 & 11 & 16.9 & \\
\hline
\end{tabular}

Individual fasting status

Baseline sample

$\begin{array}{lllll}\leq 8 \text { hours } & 29 & 44.6 & 32 & 49.2 \\ >8 \text { hours } & 36 & 55.4 & 33 & 51.8\end{array}$

Repeated sample

$\begin{array}{lllll}\leq 8 \text { hours } & 36 & 55.4 & 36 & 55.4\end{array}$

$>8$ hours

$29 \quad 44.6 \quad 29 \quad 44.6$

Thawing cycles before

Baseline sample

$\begin{array}{lcccc}\text { No } & 56 & 86.2 & 57 & 87.7 \\ \text { Once } & 9 & 13.8 & 8 & 12.3\end{array}$

Repeated sample

$\begin{array}{lcccc}\text { No } & 63 & 96.9 & 65 & 100.0 \\ \text { Once } & 2 & 3.1 & 0 & \end{array}$

0.60

0.80

a $P$ calculated using a paired $t$-test for continuous variables and the chi-square test for categorical variables.SD: standard deviation.

\section{Methods}

\section{Study population}

The study was designed as a case-control study nested in a large population-based prospective cohort called the Northern Sweden Health and Disease Study (NSHDS). ${ }^{17}$ Within NSHDS, peripheral blood samples have been collected from the general population, with informed consent, since 1984. All collected samples are frozen within $1 \mathrm{~h}$ of the blood having been drawn and thereafter stored at $-80^{\circ} \mathrm{C}$ at Umeå University Hospital (Sweden). At the time of sample selection for this study (October 2013), NSHDS contained samples from more than 100,000 individuals. Through linkage with the Swedish Cancer Registry, we identified incident myeloma cases (diagnosed between 1997 and 2013) who had previously donated at least two pre-diagnostic blood samples within NSHDS ( $n=66)$. Cancer-free controls were selected from the same cohort, and were matched to cases, in a 1:1 ratio, for sex, age at blood sample collection ( \pm 5 months), and date of blood sample collection ( \pm 2 months) (Table 1$)$.

Case classification was performed according to ICD-O-3. ${ }^{18}$ After acquisition of clinical data by retrospectively studying the patients' records, one case was reclassified as MGUS, thus leaving 65 future myeloma cases for inclusion in the present study. The retrospective record review revealed that at the time of myeloma diagnosis, 43 cases had MM and 22 had SMM, based on the criteria of the International Myeloma Working Group (IMWG) from 2003. ${ }^{19}$ Twenty-five of the included cases were included in another study based on single samples per participant. ${ }^{12}$ This study was approved by the ethical review board at Umeå University (n. 08215M and 2017/242-31).

\section{Immune marker and M-protein assessment}

Ten immune markers were measured in duplicate in all samples $(\mathrm{n}=260)$ by a Luminex multiplex assay from Millipore (USA): MCP-3, MIP-1 $\alpha$, MIP-1 $\beta$, VEGF, FGF-2, fractalkine, TGF- $\alpha$, IL-13, TNF- $\alpha$, and IL-10. Samples from matched cases and controls were included in random order in the same analytical batch. Laboratory personnel were blinded concerning case-control status and chronological order of samples. All analyses were performed according to the manufacturer's protocol (Online Supplementary Methods).

M-proteins were assessed in samples from all future myeloma cases except four (due to insufficient sample volumes) by protein electrophoresis, immunofixation electrophoresis, and FLC assays (Online Supplementary Methods).

\section{Statistical analyses}

Immune marker concentrations were $\log _{10}$-transformed for normalization. Multiple imputation was applied to attain concentration values when measurements were below the limit of quantification (3.4\% of all data points). ${ }^{20}$ Differences in immune marker trajectories between cases and controls were investigated by linear mixed models as described elsewhere, ${ }^{21}$ using the lme4 package in the R environment for statistical computing (The R Foundation for Statistical Computing) (Online Supplementary Methods).

The effect of immune marker levels on the probability of progression to MM was evaluated by Kaplan-Meier plots and the logrank test. For Kaplan-Meier estimates, time was calculated from repeated pre-diagnostic blood sample collection to either diagnosis of a treatment-requiring condition or latest follow-up without signs of progression. To define cut-off values for immune marker concentrations between individuals progressing to $\mathrm{MM}$ and others without signs of progression, we performed receiver operating characteristic (ROC) analyses. Hazard ratio (HR) associations for risk factors of progression including dichotomized immune mark- 
er level, M-protein level, ${ }^{8}$ type of M-protein, ${ }^{22}$ FLC ratio, ${ }^{8}$ and depression of two uninvolved immunoglobulins, ${ }^{8}$ were examined by using a multivariable Cox proportional-hazard model. Testing the proportional hazards assumption of the applied Cox model, we found no indication of violation. ${ }^{23}$ These analyses were performed using SPSS, version 25 (IBM). All applied biostatistical tests were two-sided.

\section{Results}

\section{Characteristics of myeloma patients}

The median times ( \pm standard deviation, SD) from the pre-diagnostic baseline and repeated samples to myeloma diagnosis were $12.8 \pm 4.5$ and $3.9 \pm 3.8$ years, respectively. By means of protein electrophoresis, immunofixation electrophoresis, and FLC assays, at the time of collection of the pre-diagnostic baseline sample MGUS was detected in $75 \%(n=46)$ of the evaluated patients, while $25 \%$ $(n=15)$ showed no signs of either MGUS or SMM. Similarly, at the time of collection of the pre-diagnostic repeated sample, MGUS was detected in $82 \%(n=50)$ and SMM in $7 \%(n=4)$ of the evaluated samples, while no signs of monoclonal gammopathy were yet found among $11 \%(n=7)$ of the samples (Figure 1). Myeloma patients were diagnosed between 1997 and $2013(n=65)$. Twentytwo cases with myeloma had SMM at diagnosis, of whom 15 progressed to MM within $2.4 \pm 4.4$ years (median \pm SD) (Figure 1). Stratified by International Staging System (ISS) stage, the median survival was 9.6 years, 5.4 years, and 4.4 years for patients with ISS 1, ISS 2, and ISS 3 , respectively (Online Supplementary Table S1).

\section{Immune marker measures and risk of progression to multiple myeloma}

Compared to controls, myeloma cases had lower levels of MCP-3, VEGF, FGF-2, fractalkine, and TGF- $\alpha$ (Table 2 and Figure 2). Plasma levels of all markers decreased among future cases, in particular TGF- $\alpha(\beta=-0.019, P=2.5$ $\left.\times 10^{-4}\right)$. In contrast, marker levels did not change significantly over time among controls (Table 2). The levels of VEGF, FGF-2, fractalkine, and TGF- $\alpha$ seemed to be higher in cases than in controls 20 to 25 years prior to diagnosis (Figure 2) although the differences did not reach statistical significance within these analyses (data not shown). We performed several sensitivity analyses to evaluate the robust-

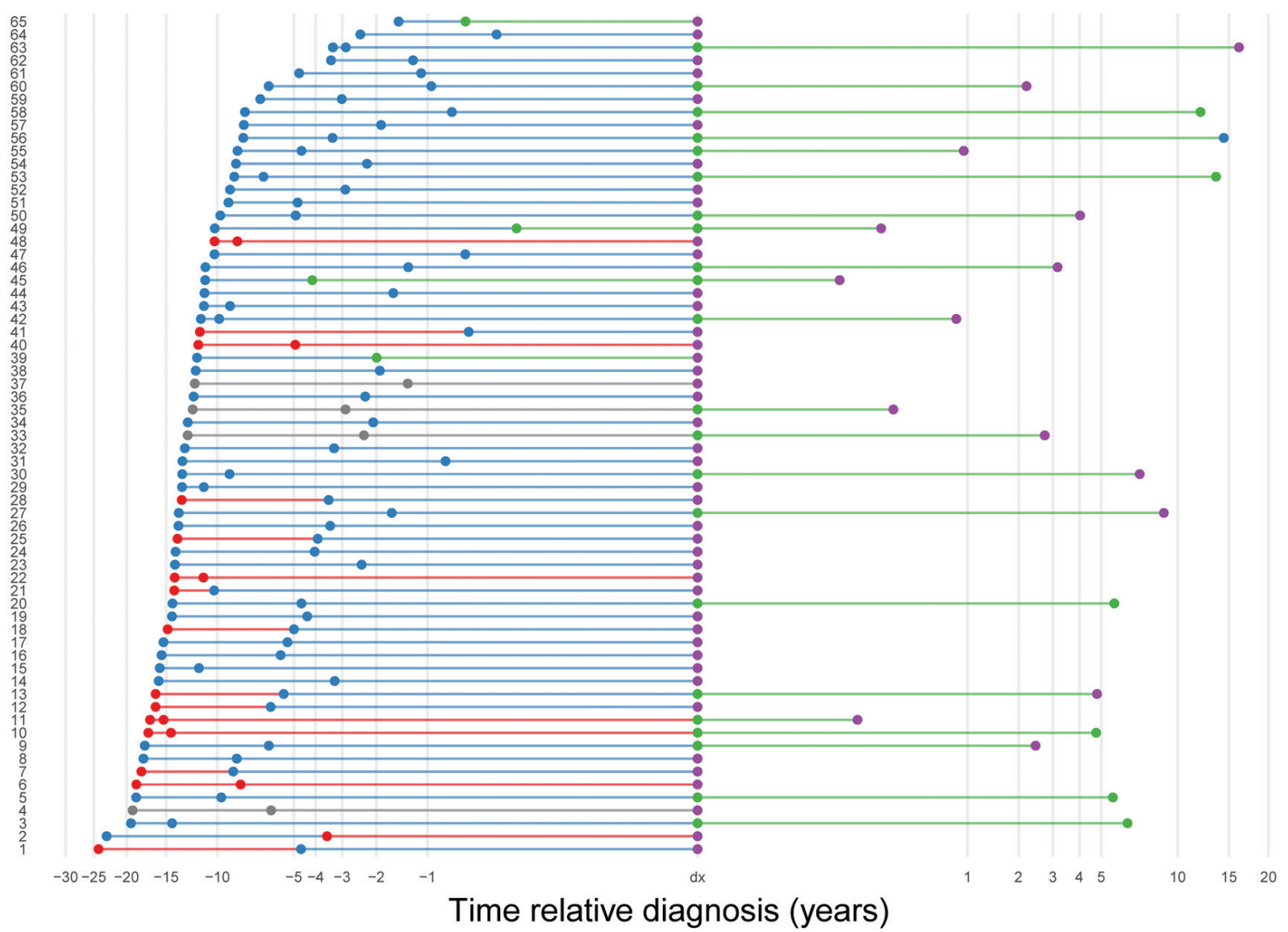

$\bullet$ no signs of MGUS $\bullet-$ MGUS $\bullet-\mathrm{SMM} \rightarrow \mathrm{MM} \longrightarrow$ NA

Figure 1. Overview of the pre-diagnostic samples for each included case (1-65) with respect to disease status during the study period. The $x$-axis is scaled around the myeloma diagnosis for a clearer overview. Pre-diagnostic disease status was determined for 61 individuals. MGUS: monoclonal gammopathy of undetermined significance; SMM: smoldering multiple myeloma; MM: multiple myeloma; NA: not available. 
ness of our findings. First, we excluded 25 myeloma cases who were part of a previous study using one pre-diagnostic blood sample for each participant. ${ }^{12}$ Results of these analyses rendered wider confidence intervals for $\beta$ estimates but remained largely similar, without affecting the interpretation. Furthermore, we investigated the influence of repeated freezing and thawing by excluding previously thawed plasma samples $(n=19)$, without finding evidence that this influenced the results. In addition, to evaluate whether individual participants influenced results particularly, we performed analyses by repeating all data modeling with stepwise exclusion of each individual (leave-oneout). Excluding individual participants did not affect the interpretation of our results.

Considering the natural history of $\mathrm{MM}$, we hypothesized that low immune marker levels in samples collected closer to diagnosis (pre-diagnostic repeated samples) might be associated with shorter time of progression to $\mathrm{MM}$ (Figure 2). Investigating this, $\mathrm{ROC}$ analyses indicated the potential to predict progression to $\mathrm{MM}$ for repeated measures of MCP-3, FGF-2, fractalkine, and TGF- $\alpha$. Low levels [defined by the ROC analyses (Online Supplementary Table S2)] of MCP-3, FGF-2, and TGF- $\alpha$ were associated with a shorter time to MM progression (Figure 3). The greatest accuracy in predicting progression to $\mathrm{MM}$ was observed for TGF- $\alpha$ at the time of the pre-diagnostic repeated sample [area under the curve (AUC) $0.75,95 \%$ confidence interval (95\% CI): 0.60-0.90] (Online Supplementary Figure S1). To investigate the value of TGF$\alpha$ as a predictor of progression to MM, we included dichotomized levels in a multivariable Cox proportionalhazard model together with known risk factors for progression. This model demonstrated that TGF- $\alpha$ remained an independent risk factor for progression (Table 3).

Risk-stratifying patients with MGUS at the time of the pre-diagnostic repeated sample into two groups, low- or low-intermediate risk and high-intermediate or high-risk MGUS, based on criteria suggested by Kyle et al., ${ }^{4}$ showed that low plasma levels of TGF- $\alpha$ might be associated with shorter time to progression to $\mathrm{MM}$ among patients with low- and low-intermediate risk MGUS (Figure 4). Low levels of TGF- $\alpha$ might also add prognostic information to

Table 2. Linear mixed modeling of marker levels for all myeloma cases, multiple myeloma cases and smoldering multiple myeloma cases in relation to 65 cancer-free controls.

\begin{tabular}{|c|c|c|c|c|c|c|c|}
\hline \multirow[t]{2}{*}{ Parameter ${ }^{a}$} & & \multicolumn{2}{|c|}{ All cases ( $(\mathrm{N}=65)$} & \multicolumn{2}{|c|}{$M M^{b}(N=43)$} & \multicolumn{2}{|c|}{$S_{M M} M^{\circ}(N=22)$} \\
\hline & & $\beta$ & $P$ & $\beta$ & $P$ & $\beta$ & $P$ \\
\hline MCP-3 & $\begin{array}{l}\text { Control-Case }^{\mathrm{d}} \\
\text { Controls x Time } \\
\text { Cases x Time }\end{array}$ & $\begin{array}{l}-0.129 \\
-0.002 \\
-0.008\end{array}$ & $\begin{array}{l}0.029 \\
0.560 \\
0.011\end{array}$ & $\begin{array}{l}-0.153 \\
-0.002 \\
-0.008\end{array}$ & $\begin{array}{l}0.028 \\
0.560 \\
0.032\end{array}$ & $\begin{array}{l}-0.067 \\
-0.002 \\
-0.005\end{array}$ & $\begin{array}{l}0.420 \\
0.601 \\
0.405\end{array}$ \\
\hline MIP-1 $\alpha$ & $\begin{array}{l}\text { Control-Case } \\
\text { Controls x Time } \\
\text { Cases x Time }\end{array}$ & $\begin{array}{l}-0.018 \\
-0.006 \\
-0.010\end{array}$ & $\begin{array}{l}0.776 \\
0.094 \\
0.004\end{array}$ & $\begin{array}{l}-0.046 \\
-0.006 \\
-0.011\end{array}$ & $\begin{array}{l}0.515 \\
0.091 \\
0.005\end{array}$ & $\begin{array}{l}0.050 \\
-0.006 \\
-0.006\end{array}$ & $\begin{array}{l}0.591 \\
0.109 \\
0.349\end{array}$ \\
\hline MIP-1 $\beta$ & $\begin{array}{l}\text { Control-Case } \\
\text { Controls x Time } \\
\text { Cases x Time }\end{array}$ & $\begin{array}{l}-0.063 \\
-0.003 \\
-0.009\end{array}$ & $\begin{array}{c}0.143 \\
0.214 \\
9.9 \times 10^{-5}\end{array}$ & $\begin{array}{l}-0.083 \\
-0.003 \\
-0.009\end{array}$ & $\begin{array}{l}0.094 \\
0.243 \\
0.001\end{array}$ & $\begin{array}{l}-0.023 \\
-0.002 \\
-0.008\end{array}$ & $\begin{array}{l}0.722 \\
0.245 \\
0.069\end{array}$ \\
\hline VEGF & $\begin{array}{l}\text { Control-Case } \\
\text { Controls x Time } \\
\text { Cases x Time }\end{array}$ & $\begin{array}{l}-0.128 \\
-0.001 \\
-0.012 \\
\end{array}$ & $\begin{array}{c}0.021 \\
0.820 \\
2.2 \times 10^{-4}\end{array}$ & $\begin{array}{l}-0.170 \\
-0.001 \\
-0.013 \\
\end{array}$ & $\begin{array}{l}0.009 \\
0.794 \\
0.001 \\
\end{array}$ & $\begin{array}{l}-0.035 \\
-0.001 \\
-0.009 \\
\end{array}$ & $\begin{array}{l}0.641 \\
0.775 \\
0.161 \\
\end{array}$ \\
\hline FGF-2 & $\begin{array}{l}\text { Control-Case } \\
\text { Controls x Time } \\
\text { Cases x Time }\end{array}$ & $\begin{array}{l}-0.101 \\
-0.002 \\
-0.010\end{array}$ & $\begin{array}{c}0.024 \\
0.324 \\
4.0 \times 10^{-5}\end{array}$ & $\begin{array}{l}-0.128 \\
-0.003 \\
-0.010\end{array}$ & $\begin{array}{l}0.014 \\
0.348 \\
0.002\end{array}$ & $\begin{array}{l}-0.047 \\
-0.002 \\
-0.011\end{array}$ & $\begin{array}{l}0.476 \\
0.339 \\
0.024\end{array}$ \\
\hline Fractalkine & $\begin{array}{l}\text { Control-Case } \\
\text { Controls x Time } \\
\text { Cases x Time }\end{array}$ & $\begin{array}{l}-0.090 \\
-0.002 \\
-0.007\end{array}$ & $\begin{array}{l}0.026 \\
0.496 \\
0.004\end{array}$ & $\begin{array}{l}-0.131 \\
-0.002 \\
-0.008 \\
\end{array}$ & $\begin{array}{l}0.005 \\
0.531 \\
0.004\end{array}$ & $\begin{array}{r}0.003 \\
-0.002 \\
-0.002 \\
\end{array}$ & $\begin{array}{l}0.965 \\
0.460 \\
0.662\end{array}$ \\
\hline TGF- $\alpha$ & $\begin{array}{l}\text { Control-Case } \\
\text { Controls x Time } \\
\text { Cases x Time }\end{array}$ & $\begin{array}{l}-0.206 \\
-0.001 \\
-0.019\end{array}$ & $\begin{array}{c}0.029 \\
0.852 \\
2.5 \times 10^{-4}\end{array}$ & $\begin{array}{l}-0.260 \\
-0.001 \\
-0.020\end{array}$ & $\begin{array}{l}0.018 \\
0.870 \\
0.002\end{array}$ & $\begin{array}{l}0.088 \\
-0.001 \\
-0.015\end{array}$ & $\begin{array}{l}0.528 \\
0.841 \\
0.125\end{array}$ \\
\hline IL-13 & $\begin{array}{l}\text { Control-Case } \\
\text { Controls x Time } \\
\text { Cases x Time }\end{array}$ & $\begin{array}{l}-0.118 \\
-0.003 \\
-0.011 \\
\end{array}$ & $\begin{array}{l}0.238 \\
0.628 \\
0.053\end{array}$ & $\begin{array}{l}-0.165 \\
-0.003 \\
-0.014 \\
\end{array}$ & $\begin{array}{l}0.146 \\
0.582 \\
0.049\end{array}$ & $\begin{array}{l}-0.028 \\
-0.003 \\
-0.006 \\
\end{array}$ & $\begin{array}{l}0.849 \\
0.604 \\
0.570\end{array}$ \\
\hline TNF- $\alpha$ & $\begin{array}{l}\text { Control-Case } \\
\text { Controls x Time } \\
\text { Cases x Time }\end{array}$ & $\begin{array}{l}-0.049 \\
-0.003 \\
-0.006\end{array}$ & $\begin{array}{l}0.318 \\
0.306 \\
0.014\end{array}$ & $\begin{array}{l}-0.082 \\
-0.003 \\
-0.007\end{array}$ & $\begin{array}{l}0.138 \\
0.344 \\
0.027\end{array}$ & $\begin{array}{c}0.022 \\
-0.003 \\
-0.004\end{array}$ & $\begin{array}{l}0.760 \\
0.346 \\
0.415\end{array}$ \\
\hline IL-10 & $\begin{array}{l}\text { Control-Case } \\
\text { Controls x Time } \\
\text { Cases x Time }\end{array}$ & $\begin{array}{l}-0.093 \\
-0.007 \\
-0.013\end{array}$ & $\begin{array}{l}0.314 \\
0.203 \\
0.016\end{array}$ & $\begin{array}{l}-0.155 \\
-0.007 \\
-0.014\end{array}$ & $\begin{array}{l}0.145 \\
0.220 \\
0.036\end{array}$ & $\begin{array}{l}0.039 \\
-0.007 \\
-0.009\end{array}$ & $\begin{array}{l}0.772 \\
0.186 \\
0.361\end{array}$ \\
\hline
\end{tabular}

${ }^{\mathrm{a}}$ All concentration data were $\log _{10}$-transformed and winsorized prior to modeling. ${ }^{\mathrm{b}}$ Analyses restricted to cases who had MM at diagnosis. ${ }^{\mathrm{c}}$ Analyses restricted to cases who had

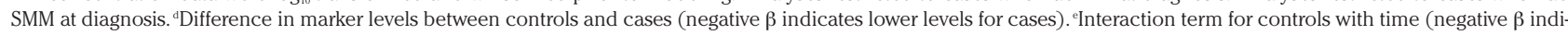
cates declining marker levels over time). Interaction term for cases with time (negative $\beta$ indicates declining marker levels closer to diagnosis). MM: multiple myeloma; SMM smoldering multiple myeloma; MCP-3: monocyte chemotactic protein-3; MIP: macrophage inflammatory protein; VEGF: vascular endothelial growth factor; FGF-2: fibroblast growth factor-2; TGF- $\alpha$ : transforming growth factor-alpha; IL: interleukin, TNF- $\alpha$ : tumor necrosis factor-alpha. 

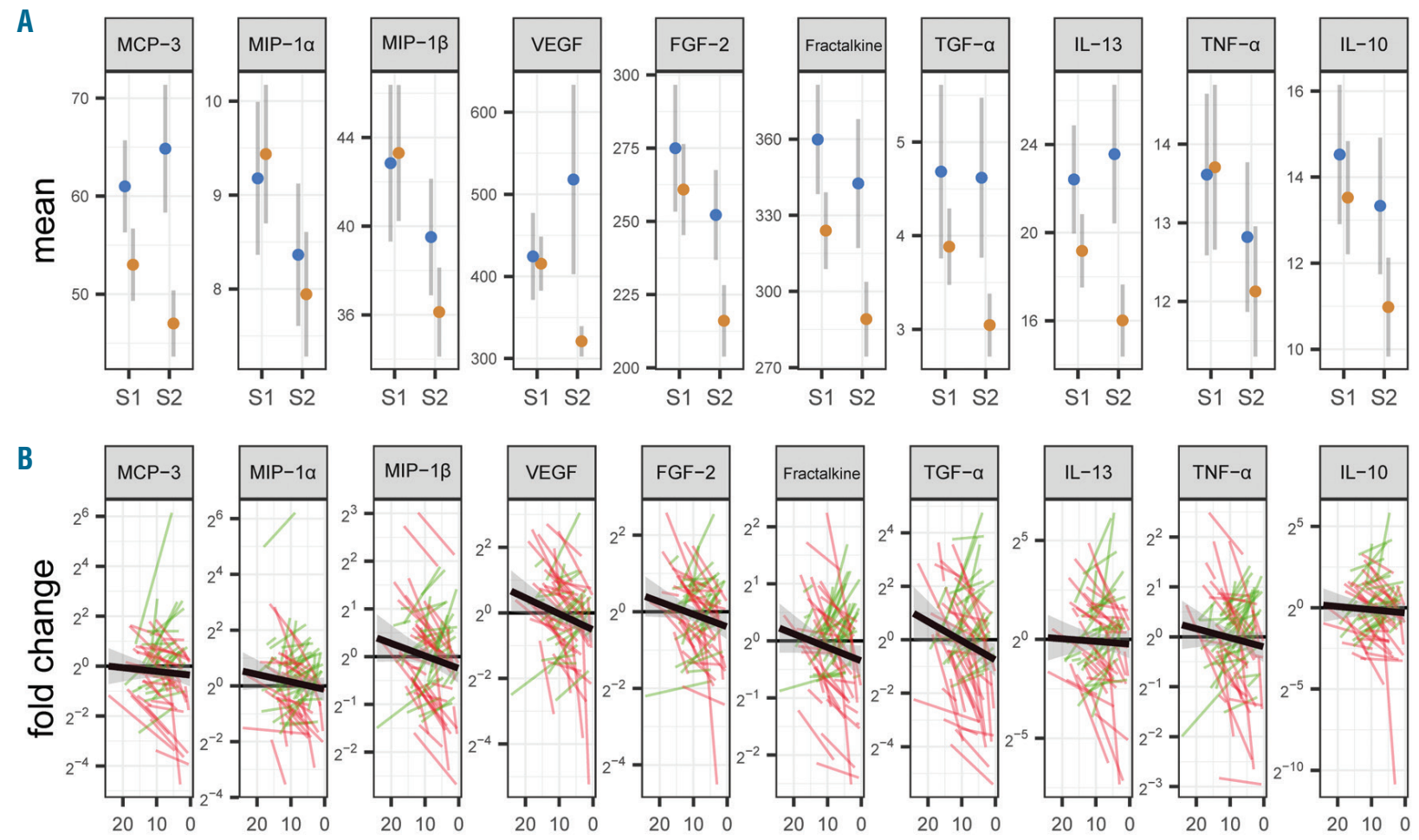

Figure 2. Trajectories of biomarker levels among 65 future myeloma patients and 65 matched cancer-free controls. (A) Mean plasma levels (pg/mL) for cases (orange) and controls (blue), grouped by pre-diagnostic baseline (S1) and repeated (S2) samples. Error bars represent the standard error of mean. (B) Fold change between the case and control for matched case-control pairs. S1 and S2 are connected with a line representing increasing (green) or decreasing (red) fold change over time. Bold lines represent linear regression over all data points. MCP-3: monocyte chemotactic protein-3; MIP: macrophage inflammatory protein; VEGF: vascular endothelial growth factor; FGF-2: fibroblast growth factor-2; TGF- $\alpha$ : transforming growth factor-alpha; IL: interleukin, TNF- $\alpha$ : tumor necrosis factor-alpha.

MGUS displaying temporally stable M-protein levels and ratios of involved FLC (Figure 4).

Analyzing baseline and repeated samples separately by logistic regression, we found risk estimates for MCP-3, VEGF, FGF-2, fractalkine, and TGF- $\alpha$ at time of the repeated sample consistent with those in the study by Vermeulen et al. based on single samples collected at a median of 6 years before diagnosis (Online Supplementary Table S3). ${ }^{12}$

\section{Intriguing clinical courses of two patients}

Patient 2 (Figure 1) had bone lesions, dominance of clonal bone marrow plasma cells, increased lambda FLC (9560 $\mathrm{mg} / \mathrm{L})$, and an IgA lambda M-spike of $1.7 \mathrm{~g} / \mathrm{L}$ at diagnosis. At 30 years of age, at the time the pre-diagnostic baseline sample was collected, MGUS was detectable (1.2 g/L IgA lambda M-spike and normal FLC). Almost 20 years later, at the time of the repeated sampling (42 months pre-diagnosis), we found no signs of MGUS and normal FLC. Of note, the TGF- $\alpha$ level decreased between sample collections and, in our analyses, was classified as low (ROC) in the repeat sample.

Patient 56 (Figure 1) was diagnosed as having SMM with $12 \%$ monoclonal kappa plasma cells. Without clinical signs of progression the patient underwent a new bone marrow examination and, based on the 2003 IMWG criteria, ${ }^{19}$ was reclassified as having MGUS 6 years after the SMM diagnosis. In this patient we observed increasing levels of TGF- $\alpha$ between samples, and the level in the repeat sample was classified as high (ROC).

\section{Correlation between predictors}

All immune markers investigated were moderately to very strongly correlated (Online Supplementary Table S4). In contrast, we found no discernable correlations between measures of TGF- $\alpha$ and known risk factors of progression including $\mathrm{M}$-protein level, $\mathrm{M}$-protein type, FLC ratio, presence or absence of immunoparesis, and total immunoglobulin levels (data not shown).

\section{Discussion}

Progression to $\mathrm{MM}$ from its precursor conditions is highly heterogeneous. ${ }^{24}$ Reliable biomarkers allowing more tailored strategies in the follow-up of MGUS and SMM are needed. ${ }^{25}$ Transformation from MGUS to MM may be a branched process, involving multiple genetic hits, immune evasion, and cell signaling mediated by cytokines and growth factors. ${ }^{26}$ Blood levels of several immune markers, such as MCP-3, MIP-1 $\alpha$, VEGF, FGF-2, fractalkine, and TGF- $\alpha$, have previously been associated with $\mathrm{MM}$ risk. ${ }^{12}$ Taking advantage of the longitudinal design of NSHDS, we here add novel information on these immune markers and their trajectories during myeloma development. In addition, we evaluated potential biomarker trajectories in relation to MGUS status and known risk factors of progression.

Our most important observations were changes in plasma levels of several immune markers among patients who subsequently developed myeloma. Given the evolution- 
A

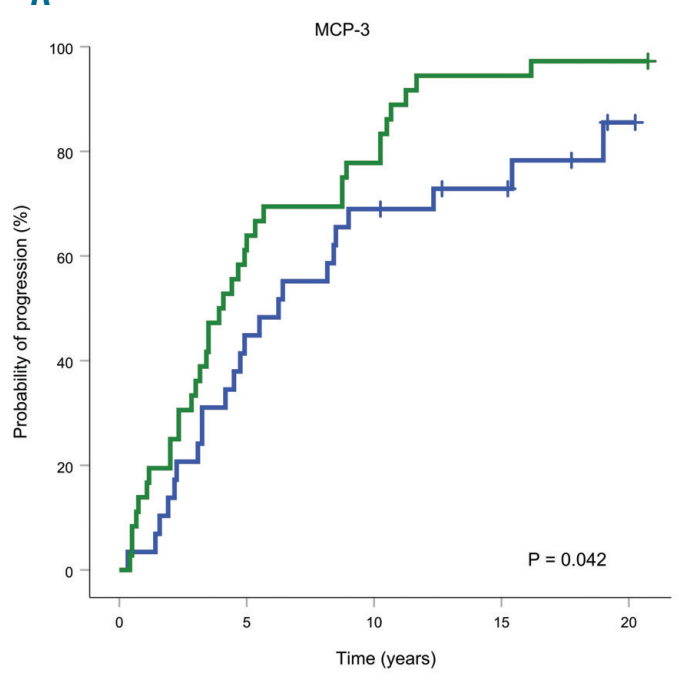

C

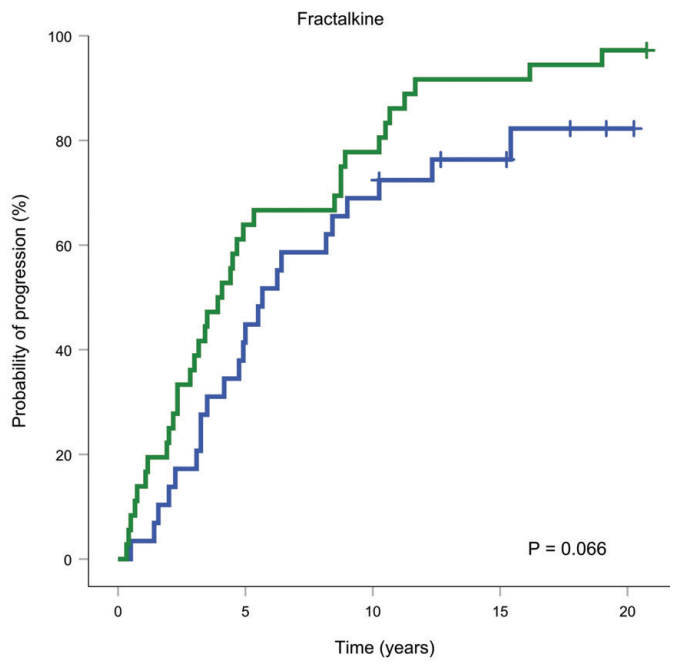

B

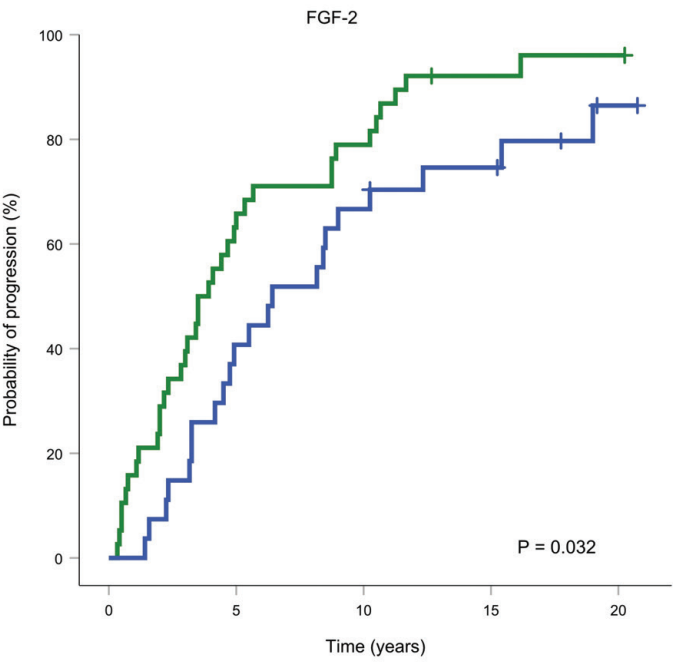

D

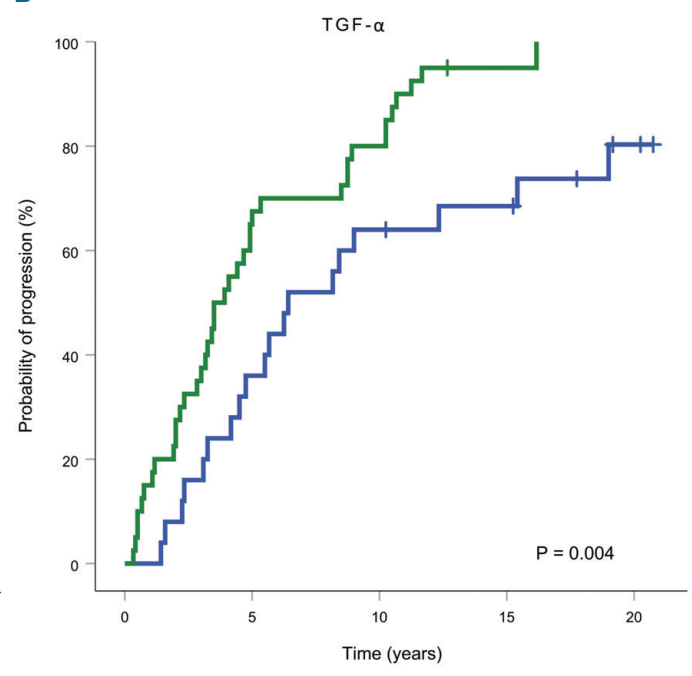

Figure 3. Probability of progression to multiple myeloma from the time of the pre-diagnostic repeated blood sampling until latest follow-up. Immune marker levels are dichotomized according to receiver operating characteristic optimized cut-off values between individuals who progressed to multiple myeloma ( $\mathrm{n}=58$ ) and individuals who did not $(n=7)$. (A-D) Patients with low levels of an immune marker are represented in green, those with high levels in blue.

ary pattern of MM, decreasing measures of VEGF, FGF-2, fractalkine, and TGF- $\alpha$ might be indicative of disease progression. The accuracy for predicting progression to $\mathrm{MM}$ was fair for pre-diagnostic repeated measures of TGF- $\alpha$, with shorter time to progression in individuals having low levels of TGF- $\alpha$ (Figure 3). Thus, TGF- $\alpha$ measured in peripheral blood, could be of interest as a candidate biomarker in the follow-up of patients with precursor conditions of MM.

The results of this study are consistent with previously published findings based on single samples per participant. ${ }^{12}$ Nevertheless, it was unexpected that low blood levels of VEGF and FGF-2 closer to myeloma diagnosis might be associated with $\mathrm{MM}$ risk and progression as these growth factors are associated with tumor angiogenesis. ${ }^{27}$ On the other hand, and more in line with our results, a recent study reported decreasing trends in plasma levels of soluble VEGFR-2 from MGUS to MM. ${ }^{11}$ Soluble VEGFR-2 is one of two soluble receptors of VEGF
Table 3. Multivariable Cox model for risk factors of progression.

\begin{tabular}{|c|c|c|c|}
\hline Risk factor & $\mathrm{HR}^{\mathrm{a}}$ & $95 \%$ CI & $P$ \\
\hline $\begin{array}{l}\text { TGF- } \alpha, p g / m L \\
\geq 3.53 \\
<3.53\end{array}$ & $\begin{array}{l}1.00 \\
3.53\end{array}$ & $1.54-8.10$ & 0.003 \\
\hline $\begin{array}{l}\text { M-protein, g/L } \\
\quad<15 \\
\geq 15\end{array}$ & $\begin{array}{l}1.00 \\
1.58\end{array}$ & $0.73-3.41$ & 0.249 \\
\hline $\begin{array}{l}\text { M-protein type } \\
\text { IgG } \\
\text { Non-IgG }\end{array}$ & $\begin{array}{l}1.00 \\
0.69\end{array}$ & $0.24-1.94$ & 0.477 \\
\hline $\begin{array}{l}\text { Immunoparesis } \\
\text { No } \\
\text { Yes }\end{array}$ & $\begin{array}{l}1.00 \\
1.20\end{array}$ & $0.57-2.53$ & 0.634 \\
\hline $\begin{array}{l}\text { FLC ratio } \\
\text { Normal } \\
\text { Abnormal }\end{array}$ & $\begin{array}{l}1.00 \\
2.05\end{array}$ & $0.66-6.31$ & 0.213 \\
\hline
\end{tabular}


A

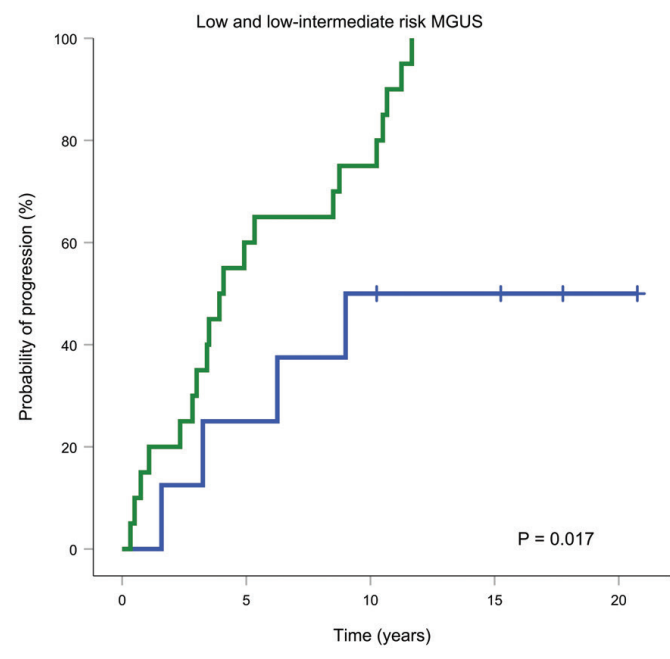

B

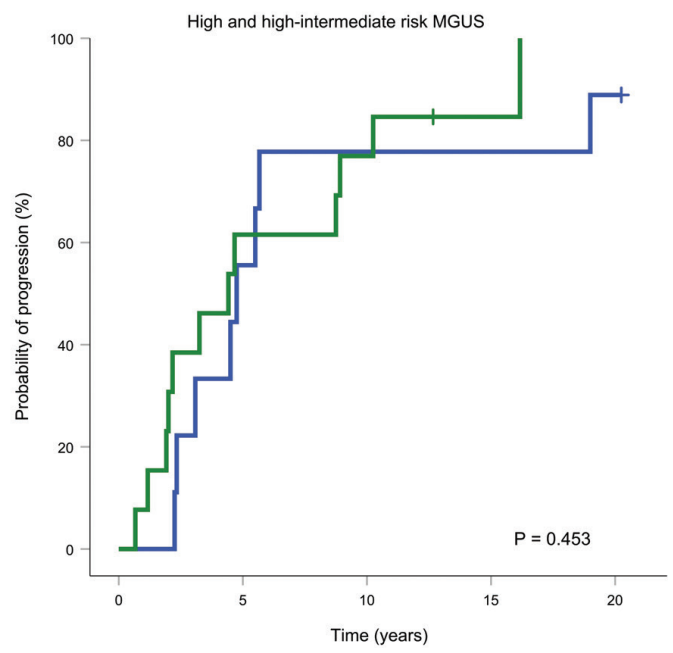

C

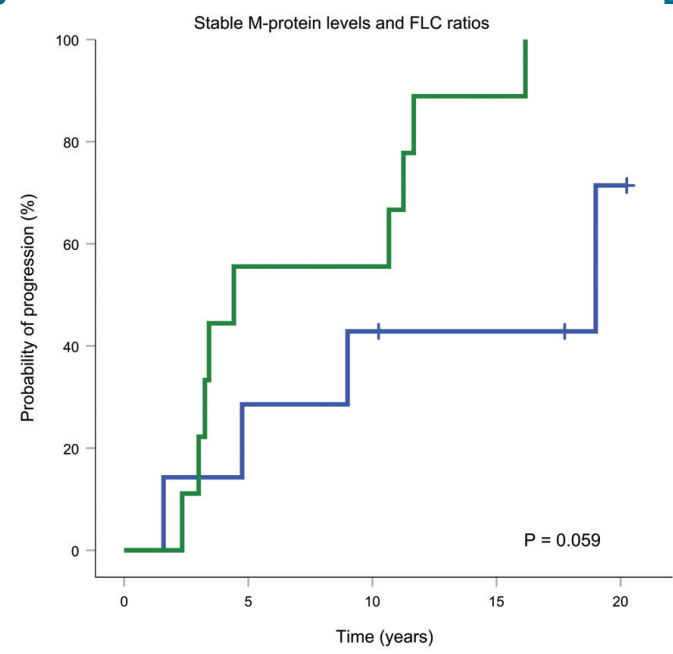

D

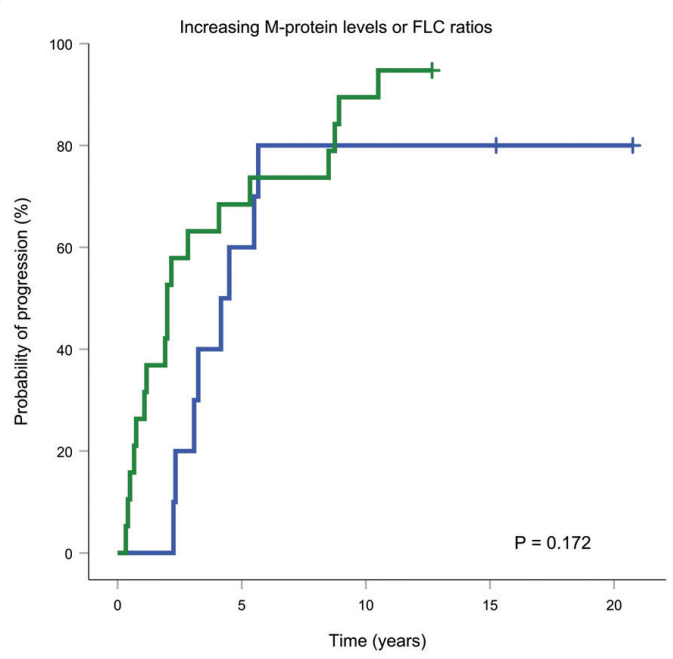

Figure 4. Probability of progression of monoclonal gammopathy of undetermined significance to multiple myeloma depending on transforming growth factor-alpha level at pre-diagnostic repeated sampling. Patients with low transforming growth factor-alpha (TGF- $\alpha$ ) levels are represented in green, those with high levels in blue. Probability of progression of monoclonal gammopathy of undetermined significance (MGUS) according to TGF- $\alpha$ levels in patients with (A) low- (no risk factor) or lowintermediate-risk (one risk factor) MGUS ( $n=28$ ) or (B) high-intermediate- (two risk factors) or high-risk (three risk factors) MGUS ( $n=22$ ). Risk factors considered were: M-protein $\geq 15 \mathrm{~g} / \mathrm{L}$, non-IgG MGUS, and abnormal free light chain (FLC) ratio. ${ }^{4}$ Risk of progression of MGUS according to TGF- $\alpha$ levels in patients with (C) stable ( $n=16$ ) or (D) increasing M-protein levels or involved FLC ratios $(n=25)$ between baseline and repeated samples. Increasing M-protein levels and involved FLC ratios were defined by an increase $\geq 25 \%$ with either an absolute rise $\geq 5 \mathrm{~g} / \mathrm{L}$ for M-protein levels or $\geq 100 \mathrm{mg} / \mathrm{L}$ for involved light chains.

and is involved in the regulation of lymphangiogenesis. ${ }^{28}$ Furthermore, serum levels of FGF-2 were found to be lower in individuals with systemic sclerosis than in healthy controls, possibly reflecting underlying defective angiogenesis in the former. ${ }^{29}$ This could be of interest as systemic sclerosis is associated with an increased risk of developing B-cell lymphoid malignancies. ${ }^{30}$ TGF- $\alpha$, a ligand of the epidermal growth factor receptor, is a mediator of oncogenesis and malignant progression. ${ }^{31}$ It is thus biologically counterintuitive that we observed decreasing plasma levels of TGF- $\alpha$ among future myeloma cases. Dysregulated blood marker levels could theoretically reflect cancer immune evasion ${ }^{32}$ or be a result of the ongoing disease process including a shift of immune-related cells towards the bone marrow microenvironment. ${ }^{33}$ However, to the best of our knowledge these processes have not been reported to involve TGF- $\alpha$. Our data indicated that the levels of VEGF, FGF-2, and TGF- $\alpha$ were higher in cases than in controls, decades before their diagnosis of MM (all $P>0.05$ ). Interestingly, it was recently shown that blood levels of VEGF and TGF- $\alpha$ are largely influenced by heritable factors. ${ }^{34}$ One might speculate that this could reflect a genetic predisposition, leading to reversed plasma levels of these proteins during the ongoing disease process. It is important to note that plasma marker levels do not necessarily reflect microenvironmental conditions in the bone marrow. This was illustrated by a small study, including $30 \mathrm{MM}$ patients and 10 healthy controls, in which higher TGF- $\alpha$ levels were observed in the bone marrow of MM patients than in controls, but levels in the peripheral blood were lower in the MM patients than in the controls, although the differences did not reach 
statistical significance $(P=0.334$ and $P=0.169$, respectively). ${ }^{35}$ Future studies, including in vitro experiments, could help to understand the role of these markers in $\mathrm{MM}$ development.

One drawback of this study was the small number of participants with repeated pre-diagnostic samples available, limiting the study's power, particularly for subgroup analyses. Nevertheless, longitudinal studies might be statistically more powerful than their counterparts based on single biological samples. ${ }^{36}$ Another drawback is the lack of bone marrow samples both at the time of pre-diagnostic sample collection and at the time of myeloma diagnosis (collected and stored for later research purpose). Such samples were not available in this cohort recruited from the general population but would have been of particular interest for investigating the trajectories of the markers in the bone marrow microenvironment. Inclusion of matched MGUS cases not progressing to MM would also have improved the study design. Limitations in study design and size might have affected the validity of the applied Cox model and may have contributed to the observation that known risk factors of progression did not reach formal significance within this analysis. Nevertheless, the study design has unique features, with its origin in repeated samples obtained prospectively from the general population.

The median survival of patients in the present cohort seemed to be longer than that of other series, ${ }^{37,38}$ which might be explained by the small and slightly younger study population, as well as a higher proportion of SMM among our cases $(33.8 \%)$ than that reported by the Swedish Myeloma Registry (14.4\%). ${ }^{39}$ All cases were diag- nosed before 2013 and the classification into SMM or MM was therefore based on IMWG criteria from $2003,{ }^{19}$ as the more recent IMWG criteria from $2014^{40}$ were not applicable. Interestingly, the number of individuals displaying high-risk SMM (as defined by a M-protein level $\geq 30 \mathrm{~g} / \mathrm{L}$ and plasma-cell infiltration of $\geq 10 \%$ ) at diagnosis $(n=6$, $9.2 \%)$ was higher than expected from other data (4.2\%). Thus, the median time of progression to $\mathrm{MM}$ among SMM patients ( $n=15)$ was 2.4 years, which is shorter than that reported by other investigators. ${ }^{41,42}$

In conclusion, we observed changes in immune markers among future myeloma patients which might be indicative of progression to MM. We found that low plasma levels of TGF- $\alpha$, measured a median of 3.9 years before the diagnosis of myeloma, were associated with a 3-fold increase in risk of progression to MM. This seemed to be independent from known risk factors of progression in a multivariable model and might therefore add useful information for early prediction of MM. The results of this study warrant further investigation, ideally in a large prospective cohort following both MGUS and SMM patients to evaluate the role of TGF- $\alpha$ as a predictor of progression to MM.

\section{Acknowledgments}

All authors would like to thank to Betty Jongerius-Gortemaker for performing excellent laboratory work (Institute for Risk Assessment Sciences, Utrecht University). The authors also thank the participants of the study, VIP and Västerbotten County Council for providing data and samples, and staff of NSHDS (Department of Biobank Research, Umea University) for their fundamental contributions to this study.

\section{References}

1. Ravi P, Kumar SK, Cerhan JR, et al. Defining cure in multiple myeloma: a comparative study of outcomes of young individuals with myeloma and curable hematologic malignancies. Blood Cancer J. 2018;8(3):26.

2. Landgren $O$, Kyle RA, Pfeiffer RM, et al. Monoclonal gammopathy of undetermined significance (MGUS) consistently precedes multiple myeloma: a prospective study. Blood. 2009;113(22):5412-5417.

3. Bianchi G, Munshi NC. Pathogenesis beyond the cancer clone(s) in multiple myeloma. Blood. 2015;125(20):3049-3058.

4. Kyle RA, Durie BGM, Rajkumar SV, et al. Monoclonal gammopathy of undetermined significance (MGUS) and smoldering (asymptomatic) multiple myeloma: IMWG consensus perspectives risk factors for progression and guidelines for monitoring and management. Leukemia. 2010;24(6):11211127.

5. Kyle RA, Remstein ED, Therneau TM, et al. Clinical course and prognosis of smoldering (asymptomatic) multiple myeloma. N Engl J Med. 2007;356(25):2582-2590.

6. Go RS, Gundrum JD, Neuner JM. Determining the clinical significance of monoclonal gammopathy of undetermined significance: a SEER-Medicare population analysis. Clin Lymphoma Myeloma Leuk. 2015;15(3):177-186.

7. Pérez-Persona E, Vidriales M-B, Mateo G, et al. New criteria to identify risk of progres- sion in monoclonal gammopathy of uncertain significance and smoldering multiple myeloma based on multiparameter flow cytometry analysis of bone marrow plasma cells. Blood. 2007;110(7):2586-2592.

8. Kyle RA, Larson DR, Therneau TM, et al. Long-term follow-up of monoclonal gam mopathy of undetermined significance. $\mathrm{N}$ Engl J Med. 2018;378(3):241-249.

9. Landgren $\bigcirc$. Monoclonal gammopathy of undetermined significance and smoldering multiple myeloma: biological insights and early treatment strategies. ASH Education Program Book. 2013(1):478-487.

10. Cosemans C, Oben B, Arijs I, et al. Prognostic biomarkers in the progression From MGUS to multiple myeloma: a systematic review. Clin Lymphoma Myeloma Leuk. 2018(4):235-248.

11. Mailankody S, Devlin SM, Korde N, et al. Proteomic profiling in plasma cell disorders: a feasibility study. Leuk Lymphoma. 2017; 58(7):1757-1759.

12. Vermeulen R, Saberi Hosnijeh F, Bodinier B, et al. Pre-diagnostic blood immune markers, incidence and progression of B-cell lymphoma and multiple myeloma: univariate and functionally informed multivariate analyses. Int J Cancer. 2018;143(6):13351347.

13. Abe M, Hiura K, Wilde J, et al. Role for macrophage inflammatory protein (MIP)- $1 \alpha$ and MIP-1 $\beta$ in the development of osteolytic lesions in multiple myeloma. Blood. 2002; 100(6):2195-2202.
14. Prabhala RH, Pelluru D, Fulciniti $M$, et al. Elevated IL-17 produced by Th17 cells promotes myeloma cell growth and inhibits immune function in multiple myeloma. Blood. 2010;115(26):5385-5392.

15. Hideshima T, Chauhan D, Schlossman R, Richardson P, Anderson KC. The role of tumor necrosis factor $\alpha$ in the pathophysiology of human multiple myeloma: therapeutic applications. Oncogene. 2001;20(33): 4519-4527.

16. Kovacs E. Interleukin-6 leads to interleukin10 production in several human multiple myeloma cell lines. Does interleukin-10 enhance the proliferation of these cells? Leuk Res. 2010;34(7):912-916.

17. Hallmans G, Agren $\AA$, Johansson G, et al. Cardiovascular disease and diabetes in the Northern Sweden Health and Disease Study Cohort- evaluation of risk factors and their interactions. Scand J Public Health Suppl. 2003;61:18-24

18. Fritz A, Percy C, Jack A, et al. International Classification of Diseases for Oncology, third edition. Geneva, World Health Organization. 2000.

19. The International Myeloma Working G. Criteria for the classification of monoclonal gammopathies, multiple myeloma and related disorders: a report of the International Myeloma Working Group. Br J Haematol. 2003;121(5):749-757.

20. Lubin JH, Colt JS, Camann D, et al. Epidemiologic evaluation of measurement data in the presence of detection limits. 
Environ Health Perspect. 2004;112(17):16911696.

21. Späth F, Wibom C, Krop EJM, et al. Biomarker dynamics in B-cell lymphoma: a longitudinal prospective study of plasma samples up to 25 years before diagnosis. Cancer Res. 2017;77(6):1408-1415

22. Kyle RA, Therneau TM, Rajkumar SV, et al. A long-term study of prognosis in monoclonal gammopathy of undetermined significance. N Engl J Med. 2002;346(8):564-569.

23. Delgado J, Pereira A, Villamor N, LópezGuillermo A, Rozman C. Survival analysis in hematologic malignancies: recommendations for clinicians. Haematologica. 2014; 99(9):1410-1420

24. Zingone A, Kuehl WM. Pathogenesis of monoclonal gammopathy of undetermined significance (MGUS) and progression to multiple myeloma. Semin Hematol. 2011; 48(1):4-12.

25. Landgren O, Kyle RA, Rajkumar SV. From myeloma precursor disease to multiple myeloma: new diagnostic concepts and opportunities for early intervention. Clin Cancer Res. 2011;17(6):1243-1252.

26. Pawlyn C, Morgan GJ. Evolutionary biology of high-risk multiple myeloma. Nat Rev Cancer. 2017;17(9):543-556.

27. Korc M, Friesel RE. The role of fibroblast growth factors in tumor growth. Curr Cancer Drug Targets. 2009;9(5):639-651.

28. Maehana S, Nakamura M, Ogawa F, et al.
Suppression of lymphangiogenesis by soluble vascular endothelial growth factor receptor- 2 in a mouse lung cancer model. Biomed Pharmacother. 2016;84:660-665.

29. Igen U, Yayla ME, Düzgün N. Low serum fibroblast growth factor 2 levels not accompanied by increased serum pentraxin 3 levels in patients with systemic sclerosis. Clin Rheumatol. 2017;36(2):367-372.

30. Zeineddine N, Khoury LE, Mosak J. Systemic sclerosis and malignancy: a review of current data. J Clin Med Res. 2016; 8(9):625-632.

31. Awwad RA, Sergina N, Yang H, et al. The role of transforming growth factor $\alpha$ in determining growth factor independence. Cancer Res. 2003;63(15):4731-4738.

32. Vinay DS, Ryan EP, Pawelec G, et al Immune evasion in cancer: mechanistic basis and therapeutic strategies. Semin Cancer Biol. 2015;35 Suppl:S185-S198.

33. Fairfield H, Falank C, Avery L, Reagan MR. Multiple myeloma in the marrow: pathogenesis and treatments. Ann N Y Acad Sci. 2016;1364(1):32-51

34. Brodin P, Jojic V, Gao T, et al. Variation in the human immune system is largely driven by non-heritable influences. Cell. 2015;160(12):37-47.

35. Kara IO, Sahin B, Gunesacar R, Unsal C. Clinical significance of hepatocyte growth factor, platelet-derived growth factor- $\mathrm{AB}$, and transforming growth factor- $\alpha$ in bone marrow and peripheral blood of patients with multiple myeloma. Adv Ther. 2006; 23(4):635-645.

36. Lu N, Han Y, Chen T, et al. Power analysis for cross-sectional and longitudinal study designs. Shanghai Arch Psychiatry. 2013; 25(4):259-262

37. Greipp PR, Miguel JS, Durie BGM, et al International Staging System for multiple myeloma. J Clin Oncol. 2005;23(15):34123420

38. Kumar SK, Dispenzieri A, Lacy MQ, et al Continued improvement in survival in multiple myeloma: changes in early mortality and outcomes in older patients. Leukemia. 2014:28(5):1122-1128.

39. Kristinsson SY, Holmberg E, Blimark C Treatment for high-risk smoldering myeloma. N Engl J Med. 2013;369(18):1762-1765.

40. Rajkumar SV, Dimopoulos MA, Palumbo A, et al. International Myeloma Working Group updated criteria for the diagnosis of multiple myeloma. Lancet Oncol. 2014; 15(12):538-548.

41. Fernández de Larrea $\mathrm{C}$, Isola I, Pereira $\mathrm{A}$, et al. Evolving M-protein pattern in patients with smoldering multiple myeloma: impact on early progression. Leukemia. 2018; 32(6):1427-1434.

42. Ravi P, Kumar S, Larsen JT, et al. Evolving changes in disease biomarkers and risk of early progression in smoldering multiple myeloma. Blood Cancer J. 2016;6(7):e454. 